\title{
Las Aboliciones de la Esclavitud en Iberoamérica: El Caso Peruano (1812-1854) ${ }^{1}$
}

\author{
Abolition of slavery in Latin America: The Peru case (1812-1854)
}

\author{
Abolição da escravatura Na América Latina: \\ Caso peruano (1812-1854)
}

\author{
María Julia de Vinatea ${ }^{2}$ \\ La Sorbonne Paris IV - Centre Roland Mousnier - Francia \\ maria.devinatearios@gmail.com
}

Recepción: 31/10/2012

Evaluación: 14/03/2013

Aceptación: 15/05/2014

Artículo de Reflexión

\section{RESUMEN}

Nuestra meta es tratar el tema de la abolición en Perú circunscribiéndola dentro de un proceso mayor que vendría a ser la circulación de las ideas abolicionistas, ante todo en el continente Americano. En este artículo intentaremos de ver el caso peruano dentro de un fenómeno global pero también dentro de sus especificidades. En efecto ya que por ser un país alejado del polo de la trata Atlántica, con un litoral mirando hacia el Pacífico, y estar compuesto por una población en su aplastante mayoría de origen indígena; tanto las características de la trata, de la esclavitud como de la abolición, hacen muy específico el caso peruano.
Palabras claves: Revista Historia de la Educación Latinoamericana, abolición, Perú, continente americano.

ABSTRACT
"Our aim is to talk about the topic of the
abolition in Peru, and to limit oneself to a
major process that could be the movement of
the abolitionist ideas in the whole American
continent. In this article we try to observe
the Peruvian case that emerged in a global
phenomenon but also into their specificities.
In fact, because Peru is an isolated country
from the pole of the Atlantic trade, and
with a littoral looking to the pacific, and
being composed by a population where the

$1 \quad$ Este trabajo es resultado del proyecto de investigación Discursos Políticos de Criollos Ilustrados en las Independencias Americanas (código SGI: 1128), avalado por el Consejo Superior de Investigaciones Científicas (CSIC) y la Universidad Pedagógica y Tecnológica de Colombia (UPTC). Esta investigación fue desarrollada por el grupo Ilustración en América Colonial (ILAC), reconocido y visible por Colciencias.

2 Doctorado en Historia. Tesis: L'abolition de l'esclavage dans les Amériques hispanophones; Luiz Felipe de Alencastro Transmision de la ideas liberales, abolicionistas, revolucionarias. La esclavitud interamericana tras la abolicion de la trata. las relaciones internacionales y diplomaticas entre potencias y paises latinoamericanos. Las formas contestatarias de los esclavos. la lucha juridicolegal y mediatica 
vast majority has indigenous origin; all the characteristics of the trade of the slavery as well as the abolition, these make very specific the Peruvian case".

Key words: Journal History of the LatinAmerican Education, Abolition, Peru, American Continent.

\section{RESUMO}

A abolição da escravatura na América Latina: o caso do Peru (1812-1854)

Nosso objetivo é tratar o tema da abolição no Peru, circunscrevendo-a dentro de um processo maior que viria a ser a circulação das ideias abolicionistas em todo o continente americano. Neste artigo, buscaremos analisar o caso peruano dentro de um fenômeno global, mas também considerando suas especificidades. $\mathrm{Na}$ verdade, já que se trata de um país afastado do polo do tráfico do Atlântico, com um litoral de frente ao Pacífico, e por ser composto por uma população de maioria esmagadora de origem indígena, as características do tráfico, tanto quanto da escravidão e da abolição, fazem do caso peruano algo muito específico.

Palavras-chave: Revista de História da Educação Latino-americana, abolição, Perú, continente americano.

\section{INTRODUCCIÓN}

La globalidad del tema de las aboliciones de la esclavitud en Iberoamérica y el largo periodo que las embarca hacen menester la metodología comparativa. En efecto, la erosión del sistema esclavista arrancó en el espacio iberoamericano a principios del siglo con Santo Domingo, en 1801, para acabar con la abolición en Cuba en 1886, "joya de las Antillas" del Imperio Español. Otro fuerte del método comparativo es el de aprehender toda la complejidad del espacio ibérico que no sólo corresponde a un territorio dado, sino a una cosmovisión dentro de una historia colonial común compartida con España. Este método permite plantearnos este espacio tal como los contemporáneos del siglo XIX se lo imaginaban; es decir, en una continuidad cultural y lingüística heredadas de la colonia y, al mismo tiempo, en una ruptura de afirmación y de consolidación de la construcción nacional.

Asimismo, no se ha repetido lo suficiente, pero la Iberoamérica del siglo XIX era ya un espacio mundializado donde transitaban tanto mercancías, extranjeros, esclavos, traducciones de libros como Uncle Tom's Cabin (EE.UU.: 1851), así como ideas revolucionarias europeas y propias de América, como por ejemplo: la revolución en Haití. Por otra parte, el tema abolicionista es sumamente complejo y global. Para empezar, la palabra apareció de manera tardía en el vocabulario periodístico inglés, a principios del siglo XIX, es decir, posteriormente a la abolición decretada por la Convención francesa y la revolución haitiana. Además, hay el peligro de que se lleve el tema de manera muy restrictiva y se haga caso omiso de la vivencia y las luchas de los propios esclavos. Cierto es que las voces esclavas resultan escasas para el historiador, puesto que la lógica de la dominación las ha silenciado durante varios siglos: ¿hasta qué punto las violencias del siglo XIX en Iberoamérica alientan la intricada modernización del pensar? ¿Cuál es el grado de relación entre el discurso caudillista y el establecimiento de medidas abolicionistas?

De ahí, la urgencia de aplicar un método histórico a la altura de la complejidad de las temáticas, para establecer puentes, relacionar o oponer países y conceptos, entrecruzar y dar cuenta de la hibridación iberoamericana. En efecto, salta casi a los ojos la interacción de nociones como: "independencia", "libertad", "imperio", "trata negrera", "esclavitud", "negros, pardos 
y libertos", "abolición gradual e inmediata", etc.; estallidos de una concepción del mundo en plena efervescencia, reordenación y transición.

\section{Panorama de las aboliciones en Iberoamérica}

\section{Por una historia comparada de los movimientos independentistas y abolicionistas}

Perú fue uno de los últimos países de América del Sur que declaró la abolición y el último, si nos enfocamos solamente en los antiguos territorios continentales de lengua española. No obstante, Paraguay hizo figura de caso aparte en las dinámicas abolicionistas del continente por sus relaciones intricadas con Argentina y Brasil. Así pues, lo que se intenta evidenciar sería la importancia de lo que está en juego, la fuerte resistencia esclavista y, ante todo, la supervivencia del conservadurismo republicano, hilo conductor heredado de la Colonia. En nuestra opinión, establecer un paralelismo entre el movimiento independentista y abolicionista es de sumo interés para la investigación científica; sobre todo, porque hasta el momento carecen de tal los estudios comparativos sobre el abolicionismo americano, como bien nos lo plantea el historiador estadounidense Omar H. Ali, en su artículo vanguardista. ${ }^{3}$ De hecho, parece haber habido dos grandes olas abolicionistas que recuerdan las campañas de independencia del sur y del norte. Dos mismos movimientos, ya sean simétricos, ya sean asimétricos respecto al primer patrón. Entre las oposiciones tenemos las iniciativas jurídicas de la abolición total que no provinieron, como se puede pensar, de los países cuna de las independencias, sino de aquellos de la primera zona de influencia. Este arquetipo fue válido para Argentina, que esperó hasta 1853 para liberar a los esclavos y Venezuela, que adoptó la misma posición un año más tarde, superando a Perú tan sólo unos meses (el 24 de marzo de 1854). Por el contrario, cerca de sus periferias, para Argentina, Chile, Bolivia y Uruguay se inclinaron a favor de la abolición total el 10 de enero de 1823, en 1831, 1830 y 1844, respectivamente. En el entorno de Venezuela, Colombia y Ecuador, de modo menos pronunciado, anticiparon la promulgación de Caracas en 1851 y 1852. Así, en oposición al esquema de la independencia, fueron los territorios periféricos que jugaron un papel protagónico principal, antes de llegar a los corazones de Argentina y Venezuela. Para completar esta comparación, el proceso abolicionista en América hispana culminó donde treinta años atrás se batalló para salvaguardar la independencia, es decir, en la sierra central del Perú: Junín y Ayacucho, en 1824. Cartográficamente, en la misma región central, un tanto más al norte, en la ciudad de Huancayo, el Perú se resignó a seguir el ejemplo de sus vecinos el 12 de marzo de 1854 (ver tabla 1).

TABLA 1 Cuadro cronológico de las principales leyes abolicionistas en el espacio ibérico

\begin{tabular}{|l|c|c|c|}
\hline \multicolumn{1}{|c|}{ Futuros países } & $\begin{array}{c}\text { Abolición de la } \\
\text { trata }\end{array}$ & libertad de Vientres & $\begin{array}{c}\text { Abolición de la } \\
\text { esclavitud }\end{array}$ \\
\hline Uruguay & 1831 & 1825 & 1842 \\
\hline Paraguay & & 1842 & 1869 \\
\hline Chile & 1811 & 1811 & 1823 \\
\hline
\end{tabular}

3 Omar H. Ali, Abolicionismo en Americas: hacia un estudio comparativo de Historia Mundial. (Bogotá: Pontifica Universidad Javeriana, CASO, Tawson University, 2005). Disponible en: http://www.uncg.edu/afs/faculty/omar_ali/ali_publications/ Abolitionism_in_the_Americas.pdf (consultado el 9 de diciembre de 2012). 


\begin{tabular}{|c|c|c|c|}
\hline Bolivia & 1826 & 1826 & 1851 \\
\hline Argentina & 1813 & & 1853 \\
\hline Perú & 1821 & 1821 & 1854 \\
\hline Ecuador & 1823 & 1821 & 1852 \\
\hline Colombia & 1823 & 1821 & 1851 \\
\hline Venezuela & 1823 & 1821 & 1854 \\
\hline Panamá & 1823 & 1821 & 1851 \\
\hline Guatemala & & & 1824 \\
\hline Costa Rica & & & 1824 \\
\hline Nicaragua & & & 1824 \\
\hline Honduras & & & 1824 \\
\hline El Salvador & & & 1824 \\
\hline México & 1821 & 1821 & 1829 \\
\hline Cuba & & 1870 & $1880-1886$ \\
\hline Puerto Rico & & 1870 & 1873 \\
\hline $\begin{array}{l}\text { República } \\
\text { Dominicana }\end{array}$ & & 1870 & $1801-1822$ \\
\hline España Metrópoli & $\begin{array}{l}1817-1835 \\
1845-1867\end{array}$ & 1870 & $1838-1880-1886$ \\
\hline
\end{tabular}

Legénde: Países pioneros que abolieron la esclavitud antes de Abolition bill en Gran Bretaña (1833)

\section{Adentrándonos en la comparación: mentalidades de los criollos}

Detrás de la impresión de caos generado por el vacío de poder tras la invasión napoleónica y luego la violencia de las confrontaciones durante el periodo independentista, todos estos acontecimientos fueron las reminiscencias de un periodo de transición, de reordenamiento de la gobernanza política en continuidad con la organización colonial.

Uno de los principales aspectos que la comparación pone de realce es el papel político cumplido por los militares en esta autoritaria reorganización política. Primero, los principales actores políticos eran, en su gran mayoría, criollos militares de carrera del ejército colonial. Esto valía tanto para los próceres de la Patria como para los hombres políticos que decretarán las aboliciones. Así, un mismo hilo conductor unen a Miranda, Simón Bolívar y otros independentistas con las personalidades que decretaron las aboliciones de la esclavitud: general Juan José Nieto Gil (Colombia), el mariscal Ramón Castilla (Perú), el general José María Urvina (Ecuador), etc. La metodología de la Historia comparada permite apreciar de modo coherente un mismo espacio y cosmovisión cuyos conflictos de autonomía y abolición 
están estrechamente ligados. De este modo, proponemos a continuación, basándonos en los aportes de la historiadora María Teresa Berruezo León, hacer un cuadro sociológico de quienes promulgaron la abolición de la esclavitud total en América hispana (1823-1854), inspirándonos en su modelo "Cuadro general de la representación americana en las Cortes de Cádiz entre 1810-1814". ${ }^{4}$

Su artículo se enfoca en la representación macrocefálica de los militares en las Cortes de Cádiz, debido a una generalización de la representación supletoria. En efecto, dado su carácter prematuro y el contexto de guerra en el que se convocó a las Cortes, pocos eran los diputados americanos "propietarios" presentes en la isla de León. Tanto así que para completar los representantes de la Indias en tan poco tiempo, se tuvo que recurrir, en la urgencia, a suplentes americanos presentes en la isla por aquel entonces. Ahora bien, para su selección, no solamente prevaleció el concepto de Derecho de suelo - haber nacido en la Indias-, sino que se requería gozar de legitimidad social dentro de los círculos americanistas, lo cual estaba estrechamente ligado a la holganza económica y el reconocimiento militar: "Con ello quiero aclarar cuál fue el peso numérico que tuvieron los militares americanos dentro del total de las diputaciones ultramarinas". ${ }^{5}$ Mientras que tan solo existe uno de los diputados propietarios militares de carrera entre 36 , los militares entre los diputados suplentes forman una aplastante mayoría de 16 entre 28 (ver tabla 2).

TABLA 2 Cuadro sociológico de los decretantes de la abolición total en Iberoamérica

\begin{tabular}{|l|l|l|l|c|l|}
\hline \multicolumn{1}{|c|}{$\begin{array}{c}\text { Nuevos } \\
\text { países }\end{array}$} & Comeriantes & Eclesiásticos & Funcionarios & Militares & Trabajadores \\
\hline Uruguay & & & & $X$ & \\
\hline Paraguay & & & & $X$ & \\
\hline Chile & & & & & \\
\hline Bolivia & & & & $X$ & \\
\hline Argentina & & & & $X$ & \\
\hline Perú & & & & $X$ & \\
\hline Ecuador & & & & $X$ & \\
\hline Colombia & & & & $X$ & \\
\hline Venezuela & & & & $X$ & \\
\hline Panamá & & & & $X$ & \\
\hline Guatemala & & & & & \\
\hline Costa Rica & & & & & \\
\hline Nicaragua & & & & & \\
\hline Honduras & & & & & \\
\hline
\end{tabular}

4 María Teresa Berruezo. La participación americana en las Cortes de Cádiz (1810-1814). (Madrid: Centro de Estudios Constitucionales, 1986).

5 Berruezo, La participación americana. 


\begin{tabular}{|l|l|l|l|l|l|}
\hline El Salvador & & & & & \\
\hline México & & & & $x$ & \\
\hline Cuba & & & \multirow{2}{*}{$\mathrm{X}$} & & \\
\cline { 1 - 3 } Puerto Rico & & & & & \\
\cline { 1 - 3 } & & & & $\mathrm{X}$ & \\
\hline $\begin{array}{l}\text { España } \\
\text { Santo } \\
\text { Domingo }\end{array}$ & & & & & \\
\hline
\end{tabular}

Fuente: adaptada de Berruezo, La participación americana,

Si bien es cierto que los diputados ultramarinos, los independentistas y los abolicionistas parecen elementos desasociados, por ejemplo, fueron escasísimos los representantes americanos rebeldes que, tras el fracaso de las Cortes, tomaron las armas a favor de una ruptura con la metrópoli: José Álvarez de Toledo y José Domingo Caicedo Siguiendo. Sin embargo, una sociología de los militares permite ver el nexo que los une. Si tal como lo teorizó Weber, el poder efectivo fue siempre una mezcla y un equilibrio entre tres componentes: poder tradicional, poder carismático y racional-legal, entonces, se entiende la debilitación del poder tradicional encarnado en el rey tras su captura, en beneficio de los dos últimos componentes. Es más, la metodología de Alain Rouquié esclarece los mecanismos de "la verticalidad de las relaciones sociales" ${ }^{\prime \prime}$ que han demostrado su fuerte arraigo, tanto en las élites, como en el pueblo. Estos elementos hicieron factible su permanencia en el tiempo.

En su estudio sobre el Ejército en América, Juan Marchena ${ }^{7}$ esclarece las relaciones imbricadas entre las élites y la armada en las Indias, puesto que resultaba más eficaz y menos costoso para la Corona delegar la cuestión de defensa del inmenso territorio colonial a la oligarquía criolla establecida allá, de tal modo que, en vísperas de la Independencia, el Ejército se había vuelto un poderoso ascensor social para muchos nobles, ricos comerciantes y terratenientes. En los hechos, "el 70\% de la oficialidad del Ejercito de Dotación (Fijo) era natural de la misma ciudad", ${ }^{8}$ aunque seguían prevaleciendo los conceptos de "limpieza de sangre" y de "preferencia peninsular" para los altos rangos de la oficialía, siendo estos motivos de tensión recurrentes entre criollos y peninsulares. Al cambiar la dinastía, las reformas ilustradas de Carlos III trastornarían las relaciones entre la élite y el pueblo. La revisión del fuero militar con un nuevo protagonismo de las milicias en las Américas permitió un alistamiento mucho más amplio, multiplicando así el impacto social de la Institución: "Eran fundamentalmente sus vecinos y moradores los que conformaban la tropa de las unidades militares; extraídos de los sectores populares, encontraban en la soldada un modo como cualquier otro de ganarse la vida, sin que ello les impidiera tener una segunda dedicación laboral y vivir en su morada excepto cuando les tocaba servicio, guardia o ronda".

Por consiguiente, era frecuente hallar gente de muy humilde estrato, como "La Compañía de Pardos Libres de Lambayeque" o "El Escuadrón de los Dragones Disciplinados de Pacasmayo", que anhelaban una mejoría de su condición social. Esta esperanza era suficiente tanto para alzar batallones completos de miserables, como para fortalecer el poderío

6 Alain Rouquié, L'Etat militaire en Amerique Latine (Paris: Editions du Seuil, 1982).

7 Juan Marchena y Manuel Chust. Armas de la nación: independencia y ciudadanía en Hispanoamérica (Madrid: Iberoamericana, 2007).

8 Allan J. Kuerthe y Juan Marchena. Soldados del Rey: el Ejército Borbónico en América colonial en vísperas de la Independencia (Castello de la Plana: Universitat Jaume I, 2005). 
tradicional de los criollos. Si bien es cierto que, en la mayoría de los casos, la guerra tan sólo proporcionaría muerte y heridos en la soldadesca; sin embargo, las contadas excepciones exitosas permitieron trazar un arquetipo de "caudillo". John Lynch dirá de las guerras independentistas que servirían d cuna para los caudillos cuyas características solían ser provenientes de hombres carismáticos, muchas veces de origen plebeyo, que controlaban tanto la vida política como económica de sus provincias. Gracias a sus armas y hombres, pudieron llevar a cabo guerras locales. Estas sumergieron las nuevas repúblicas, desde sus inicios, en guerras intestinas que acarrearon una tremenda inestabilidad política y jurídicolegal, y una de las consecuencias de este fenómeno fue precisamente el desmoronamiento acelerado de la institución esclavista en Iberoamérica continental.

\section{Abolicionistas criollos: una infinita minoría}

\section{Revolución de Haití y reacción de los criollos}

No es secreto para nadie, y menos aún para los contemporáneos, que las noticias de Haití fueron motivo de preocupación y temor. Aunque no vale encerrarse en la teoría de la contaminación - ya que nos impediría apreciar toda la ambigüedad del comportamiento criollo-, en efecto, cuando arrancan las insurrecciones esclavas del 22 y 23 de agosto de 1791, estas estuvieron estrechamente ligadas con los giros de los acontecimientos en Francia: la familia Real está bajo la estrecha vigilancia de los revolucionarios, motivo de inquietud para Carlos IV. El monarca se vio obligado a encabezar una política doble: abierta a la negociación y eficaz en el debilitamiento de los revolucionarios. De allí, el envalentonamiento de los criollos dominicanos que pensaron en sacar provecho apoderándose de las ricas tierras cañeras de los franceses y, de un mismo tiro, unir la isla bajo la bandera española. Fue así como alistaron a masas de esclavos prófugos que hicieron sus primeras armas bajo las órdenes de militares españoles. La carrera militar de Toussaint Louverture habla por sí sola.

"Negro de talento", liberado por su amo Bayon de Libertat en recompensa de sus buenos y leales servicios durante el decenio de 1770, se piensa que su instrucción militar empezó al lado de los españoles por aquellos años turbios de 1791. Tras la ejecución de Luis XVI el 21 de enero de 1793 y la seguida guerra de la Convención (1793-1795), Toussaint cobró un papel protagónico de primera orden, ya que, a la cabeza de una armada disciplinada de varios miles de negros, no carecía de argumento para seducir a las potencias coloniales. Pronto España lo honoró con el título de teniente-general. Incluso, fue por aquel entonces que ganó su apellido L'Ouverture en referencia a su talento para abrir brecha en el rango del enemigo. ${ }^{9}$ Repentinamente, por falta de sostén popular, los franceses se vieron acorralados en un espacio cada vez más exiguo, ya por los españoles, ya por los ingleses, quienes además utilizaron sus colonias en Cuba y Jamaica para contraatacar.

Las proclamaciones de abolición de la esclavitud de los comisarios Sonthonax et Polverel caen a pico, entre el 27 y 29 de agosto de $1793 ; ;^{10}$ estas motivaron el enrolamiento de muchos esclavos. Conforme fue cambiando la situación en detrimento de intereses de los hacendados blancos y

9 François Blancpain, La colonie française de Saint-Domingue (Paris: Karthala, 2004).

10 La manumisión militar era una vieja tradición del Ejército, su obtención era una suerte de recompensa después de actos de heroicidad y de particular bravura en los combates. A veces también, en un impulso de generosidad, se recurría a aquella operación solía llamarse "el rescate" de esclavos. Con la agudización del conflicto, la República francesa pone en práctica esta estrategia de la manumisión poco eficaz frente a las promesas de los bandos enemigos. España, por ejemplo, generaliza la manumisión militar, no sólo acordando la libertad a los valerosos soldados, sino que les posibilitaba una ascensión jerárquica rápida, con lo que Francia no le quedó otra alternativa que encarecer; primero, otorgando libertad a los que se alistaban bajo sus órdenes; luego ampliando los derechos sobre los familiares; para finalmente, conceder la libertad a todos los esclavos fieles. Cf. Nuria Sales de Bohigas, Esclavos, reclutas y mercaderes de quintos (Barcelona: Ariel, 1974). 
mestizos, fue acrecentándose el flujo de refugiados en destino a Santo Domingo. Seducido por la oferta de libertad total para los esclavos y en malos términos con Jean-François y Biassou (compañeros de armas bajo la bandera española), Toussaint decidió oportunamente pasarse al enemigo a principios de 1794 . Hubo un giro en el equilibrio de las fuerzas a beneficio de los franceses, que ganaron terreno hasta llegar a ocupar buena parte del lado occidental de la isla. A lo último, España se vio obligada a dejar sus posiciones del todo firmando el Tratado de Basilea el 22 julio de 1795. Los franceses quedaron con un total poderío sobre la isla, cuya presencia se hizo más visible con la invasión de Toussaint Louverture en 1801. Entretanto, las insurrecciones de esclavos se hicieron más frecuentes y poderosas en la colonia española, como lo demuestra el caso de la azucarera Boca de Nigua en octubre de 1796 -propiedad del Conde de Aranda, antiguo favorito de Carlos IV-, que funcionaba con más de 200 esclavos y quedó totalmente destruida. Para los criollos dominicanos que sufrieron la inversión de la situación, en comparación a los años 1792 y 1793, no pudieron creer en el Tratado de Basilea ni en la legitimidad del comisario Roume. Las autoridades españolas hicieron caso omiso de su persona y de su rango. ${ }^{11}$ Ahora bien, cuando Toussaint unificó la isla bajo el sello de la República francesa, proclamó leyes muchísimo más modernas, tanto para la economía y administración, como para la cosmovisión hispana, más de lo que los dominicanos habían estado acostumbrados: abolición de la esclavitud, lucha en contra la discriminación racial, acuñación de moneda, medidas económicas liberales, mejora de la enseñanza pública con mayor participación étnica, imposición del Código Rural, del primer esbozo constitucional con su nombramiento a perpetuidad, etc. Ahora bien, los criollos dominicanos, hasta aquel entonces, solamente habían conocido la tradición administrativa española volcada en negociaciones y composiciones de todo tipo, lo cual los llevaba a ser reticentes a la imposición.

Esta abrupta transición agudizó tensiones entre diferentes componentes étnicos y pronto acarreó masacres de hacendados blancos. ${ }^{12}$ Por ello, las más pudientes familias dominicanas resolvieron marcharse hacia zonas donde su fondo de comercio estuviera a salvo. Entre los lugares de predilección, tenemos a Cuba, Puerto Rico y Venezuela para los hispanohablantes, y Martinica, Guadalupe, la metrópoli para los francófonos. Esta migración ayudó a difundir de manera mundial y eficazmente "la leyenda negra de la revolución haitiana" ${ }^{13}$ Pero, por otra parte, en Venezuela, por ejemplo, los pardos simpatizaron tanto con las ideas revolucionarias de Haití, que incentivaron a la Corona a prevenirse del peligro aplicando la Real Cédula de Gracias al Sacar, con la que se podía blanquear orígenes con previo pago de un canon. Para Javier Laviña, esta medida participó claramente de una política de containment de las ideas revolucionarias, en la que el Virrey de Nueva Granada se lanzó como en una cruzada, persiguiendo y deportando a cuantos afrancesados republicanos encontraba ${ }^{14}$

Frente a la invasión napoleónica en 1802 y el restablecimiento de la esclavitud, despertó embrionariamente un sentimiento nacional independentista anti-francés y abolicionista (vendremos sobre este punto). Es evidente que esta construcción de la dominicanidad se elaboró e imaginó a través del prisma del "enemigo haitiano", no sin argumentos como la antigua competencia y recelos imperialistas de Francia y España, el sitio de Santo Domingo y las

11 Blancpain, La colonie française de Saint-Domingue.

12 María Magdalena Guerrero Cano. Santo Domingo (1795-1865) (Cádiz: Universidad de Cádiz, 1986), 122.

13 Sobre la influencia de los inmigrantes dominicanos en el conservadurismo cubano ver Karim Ghorbal, Réformisme et esclavage à Cuba (1835-1845) (Paris: Publibook, 2009). Sobre la guerra de imágenes en Europa y en el espacio Caribeño, en la que se representaron los haitianos sanguinarios, salvajes, caníbales transformándolos en el prototipo del húbris, para más información remitirse a Ernesto Sagás, Race and Politics in the Dominican Republic (Gainesville: University Press of Florida, 2000).

14 José Laviña, “¿Revolución Francesa o miedo a la negritud?: Venezuela 1790-1800”, en Coloquio Internacional sobre la Abolición de la Esclavitud (Madrid 1986): Esclavitud y Derechos Humanos. (Madrid: Consejo superior de investigaciones científicas, Centro de estudios históricos, 1990). 
masacres de Dessalines (1805). ${ }^{15}$ Ahora bien, un acercamiento se hace latente, como muy bien nos los plantea el historiador dominicano Emilio Cordero Michel: "Una profunda corriente de solidaridad con el pueblo haitiano visto como el amigo redentor" ${ }^{16}$ En efecto, es necesario evocar la diplomacia extremadamente activa de Dessalines, Petión y Boyer para contrarrestar el aislacionismo impuesto por las potencias europeas y demás vecinos, todos aun esclavistas. En primer lugar, los gobernantes haitianos apoyaron intentonas de sus vecinos no con la intensión de debilitar sino desalojar las fuerzas imperialistas. Así, se escudriñó el tercer gran enfrentamiento que desembocó en la batalla de Palo Hincado; sin olvidar el apoyo brindado a los esclavos de la Rebelión de Mojarra y Mendoza y a la ayuda sustancial a Manuel del Monte y a Don Fermín García convencidos abolicionistas. Igualmente, la diplomacia activa nutre intercambios ideológicos y políticos con el continente; Petión recibió las visitas de los ilustres libertadores Miranda (1805) y Bolívar (1815), entre muchos otros menos famosos como Don Manuel Gual y José María España. A todos estos grupos de revolucionarios se les brindó apoyo que radicaba tanto en consejos militares como en armamentos, contingente y hasta cooperación financiera cuando se pudo. Entre las consecuencias más importantes para su vecina, fue el haber dado no una, sino dos estacadas mortales a la institución esclavista cuya resistencia tenaz dio quebraderos de cabeza. ${ }^{17}$ La segunda proclama la hizo Jean François Boyer al anexionar nuevamente el territorio.

\section{De las Cortes de Cádiz en $\mathbf{1 8 1 2}$ a las sociedades abolicionistas españolas: un silenciado recorrido}

La primera impulsión fue dada por algunos raros representantes vanguardistas al momento de la redacción de la futura Constitución liberal de 1811-1812. En efecto, la polémica se acentuó particularmente cuando se evocó la cuestión de la ciudadanía y el derecho de voto en la futura monarquía constitucional española. Un periodista corresponsal del periódico El Peruano escribió, bajo el seudónimo de "un originario de África", lo siguiente:

\section{Una gran expectación me acompaña. Según ellos se estaba discutiendo el artículo 22 del proyecto de la Constitución política de la Monarquía española presentando a las Cortes generales: es un artículo que integralmente comprende y pertenece a los españoles que por cualquiera línea traemos origen de África. Negros, mulatos, zambos, chinos, cuanto vais a ser considerados en la nación española de una manera que nunca lo habéis sido ... Vamos a mudar la situación en que han vivido nuestras castas... ${ }^{18}$}

Obviamente, la proposición de ley disgustó a algunos representantes de la Asamblea, cuyas quejas se dieron a conocer en el mismo número: "Si el artículo se aprobase en los términos que se había propuesto, bastaría el solo para deslucir la Constitución española". ${ }^{19}$ Algunos días más tarde, el Coronel Francisco Salazar, diputado nacido en Lima, se solidarizó con el grupo abolicionista, pero con una proposición menos ambiciosa, lo cual demostraba su

15 Guy Alexandre, «Les relations haitiano-dominicaines: fondements et trajectoires», en De lîle espagnole à la République Dominicaine d'aujourd'hui, ed. Alain Yacou (Pointe-à-Pitre : Karthala, 2010). También referirse a Benedict Anderson, Imagined Communities: reflections on the origin and spread of nationalism (London: Verso.1991).

16 Emilio Cordero Michel, «Impact des révolutions française et haïtienne à Saint-Domingue », en Yacou, De l'île espagnole.

17 "Hasta 1822, la vida en Santo Domingo languideció al punto de llegar a extremos de absoluta indigencia económica. Era tal el estado de postración que el mismo Gobernador Sánchez Ramírez, artífice de la Reconquista, se vio obligado a cambiar negros esclavos por mercancías con que suplir las necesidades más apremiantes", cita de Carlos Esteban Deive, "La abolición de la esclavitud en SantoDomingo", en La Abolición de la Esclavitud: Esclavitud y Derechos Humanos (Madrid: Centro de Estudios Históricos, 1990).

18 “Un originario de África”, El Peruano, 3 de octubre, 1821. Biblioteca Central, Fondos Reservados de la Universidad Nacional Mayor de San Marcos: UNMSM, Lima.

19 Ibíd. 
preocupación por encontrar algún consenso con los conservadores para hacer aprobar la ley. En efecto, él hizo una propuesta de ley inédita en la que se daba la ciudadanía a todos, inclusive a los esclavos. Sin embargo, la diferenciación social se efectuaría bajo los términos de una ciudadanía "activa" o "pasiva". Los esclavos no tendrían el derecho de voto por su condición de sumisión. Los libres nacidos de una relación ilegítima tampoco lo tendrían. De hecho, se excluiría a la mayoría de libertos y pardos: "Salazar proponía que en lugar del artículo 22, que se hallaba en esos momentos en discusión, se considerase como ciudadanos a todos aquellos anotados en los libros parroquiales, ya fuera españoles o castas. Con respecto a estos últimos, en caso de ser nacidos libres y de legitimo matrimonio, contarían con voto activo; caso contrario, con voto pasivo, de acuerdo con lo que la Constitución estableciese". ${ }^{20}$

En otra ofensiva progresista, los diputados Alcocer y Argüelles propusieron acabar con el esclavismo de inmediato, prohibiendo no solamente la trata, sino también la posesión de esclavos. En 1813, los abolicionistas replantearon de nuevo sus argumentos a través de uno de sus más carismáticos representantes Isidoro d'Antillon, que fue agredido físicamente en los días siguientes. Las lesiones fueron tan importantes que no se logró salvar la vida del diputado, lo cual deja mucho que decir sobre los métodos empleados por los esclavistas para neutralizar a sus más peligrosos oponentes.

Ahora bien, si no hubiera sido por el coraje de este grupo de liberales radicales, la Corte Gaditana no tuviera la importancia simbólica en la construcción nacional que goza ahora. No sin preocupación histórica, estos representantes más progresistas se propusieron reanudar con la preponderancia pasada de España en materia jurídica, yendo incluso más allá de los planteamientos de los abolicionistas ingleses. En efecto, nos damos cuenta de que, jurídicamente, respecto al abolicionismo, la Corte Gaditana estaba tan avanzada como Gran Bretaña, considerada pionera del movimiento abolicionista, cuyas principales leyes se votaron a principios de siglo: The Foreing Slave Trade Bill (1806) y Abolition Bill (1833). Por lo tanto, sorprenden las discusiones en torno a una abolición inmediata para el Imperio español cuando el modelo inglés imperante sugería la abolición gradual. Es una paradoja para los estudiosos del espinoso tema que luego, España, de la restauración, mostrara tan poca voluntad y actitudes contra corriente para tomar medidas, quedando entre los últimos países que abolieron la esclavitud a fines del siglo XIX.

Luisa y Enriqueta Vila Vilar nos explican que siguieron existiendo voces de denuncia a lo largo del siglo, incluso en las Cortes con recurrentes debates, proyectos de ley e incluso voto de leyes..$^{21}$ Lamentablemente quedaban en papel mojado por falta de voluntad política y por el duro enfrentamiento con el lobby de plantadores esclavistas. De allí la explicación que este retraso se debiera a una relación complicada con las dos últimas colonias: Puerto Rico y Cuba, y a la problemática de la esclavitud en sí. Además, conforme España iba perdiendo sus territorios ultramarinos, los esclavistas amalgamaron temas como el patriotismo, la decadencia española, etc., con el abolicionismo. De suerte que, con una argumentación bastante rápida y sumaria, se acusaba a los abolicionistas de carecer de juicio, lealtad a la Corona y de patriotismo.

20 John Rodríguez Asti, "El discurso abolicionista en la prensa peruana (1800-1850): una aproximación al tema", en Etnicidad y discriminación racial en la Historia del Perú, ed. Ana Cecilia Carrillo (Lima: PUCP/Instituto Riva-Agüero, 1998), 147-163.

21 Enriqueta Vila Vilar y Luisa Vila Vilar, Los Abolicionistas Españoles. Siglo XIX (Madrid: Cultura Hispánica Instituto de Cooperación Iberoamericana, 1996), 103. 
En el terreno ideológico, la institución esclavista "se había venido tolerando como una lacra social molesta pero necesaria a lo largo de tres siglos". ${ }^{22}$ Así es como, más de sesenta años después, con la Société Française des amis des noirs y las primeras sociedades británicas, comenzó apenas a brotar en España una febril organización abolicionista, sobre todo, en torno de los periódicos El Abolicionista (1872-1876), La América ${ }^{23}$ (1857-1886) y La Sociedad Abolicionista Española (Madrid: 1864-1888). En este último conglomerado político, la posición mayormente asumida fue la supresión gradual de la esclavitud. La sociedad fue haciéndose fuerte hasta alcanzar los setecientos miembros, entre los cuales los más ilustres eran: Julio Vizcarrondo (portorriqueño fundador), Emilio Castelar, Rafael M. de Labra, Juan Justiniano Arribas, Apolinar Menéndez Acebal, Javier Calvete, Fernando de Castro, Antonio Carrasco, Manuel Corchado, entre otros.

\section{El caso peruano y la resistencia conservadora}

\section{El pensamiento político de los criollos independentistas y la abolición de la esclavitud}

Nuria Sales deBohigas noshace recordar quela mayor parte del esfuerzo independentista reposó sobrelos reclutas esclavos, al punto de casi vaciar Argentina y Uruguay de su población negra.En Argentina, los censos delaépoca colonial daban una proporción de 25\% de la población. En 1843, esta proporción había decaído a 7\%. Al momento de abolir totalmente la esclavitud, se pretendió que la ley tan sólo concernía a 300 personas. Entonces, cuando el Libertador, Gobernador de Cuyo, San Martín emprendió en 1820 su expedición independentista en dirección del Perú, él esperaba con certeza el respaldo de la población esclava. La propuesta de manumisión militar hubiera podido seducir en el Perú de igual manera que sedujo en la campaña de la Plata. ${ }^{24}$ Sin embargo, pese a una propaganda bien desenvuelta, con afiches y proclamaciones leídas en las principales zonas de concentración de mano de obra esclava, y la promesa de una manumisión inmediata después de su enrolamiento, dichas medidas dieron un resultado bastante limitado. Las razones del fracaso son complejas pero se pueden resumir en:

1. La expedición libertaria tuvo una progresión lenta, debido a la negociación sostenida con las autoridades coloniales que dió tiempo a los grandes propietarios esclavistas de escapar con sus esclavos, como se dio el caso del conde de Monteblanco y los Mazo, de la zona de Pisco.

2. La intricada negociación que se armaba con los hacendados esclavistas para hacerlos partícipes del esfuerzo de guerra. De ahí, las precauciones del senado chileno sobre la política abolicionista de San Martín, aconsejándole de no hacer ninguna declaración sobre el tema, ${ }^{25}$ sin duda para temporizar, puesto que en el fondo había relaciones comerciales de cierta envergadura con estos grandes propietarios esclavistas.

\footnotetext{
22 Ibíd., 12.

23 Leoncio López-Ocón Cabrera, “El movimiento abolicionista español a través la revista La América (1857-1886)”, en La Abolición de la Esclavitud : Esclavitud y Derechos Humanos (Madrid: Consejo superior de investigaciones científicas, Centro de estudios históricos, 1990).

24 Volumen colectivo, Documentos historicos del Perù. (Lima: Cia de Impresiones y Publicidad, 1946). Leer también Diego Barros Arana, Historia Jeneral de Chile, vol. 10 (Santiago de Chile: R. Jover, 1889).

25 Documento de carácter secreto redactado el 23 de junio de 1820. Referirse a Nils Jacobsen, The Development of Peru's Slave Population and its Significance for Coastal Agriculture (1792-1854) (Los Angeles: UCLA, 1974).
} 
3. La relativa debilidad del esclavismo en el Perú y la falta de cooperación de los grandes propietarios peruanos, mucho más conservadores que en Argentina, Uruguay o Chile. Además, en vista de la atmósfera revolucionaria, era de esperarse que los propietarios reforzarían el sistema de control.

4. Pero, sobre todo, lo que demostró el estudio comparativo de Sales de Bohigas fue la instrumentalización de la libertad, la dimensión oportunista de las manumisiones militares. En efecto, era en los momentos de más grandes dificultades del ejército que se dictaban las promesas de libertad. Por lo contrario, después de que la leva de tropas estaba asegurada y las necesidades menos palpables, se postergaba la aplicación de las manumisiones acordadas o simplemente se las derogaba. Esto delata no sólo la falta de voluntad política, sino que, además, refleja las prioridades de la estrategia militar.

Así pues, las medidas antiesclavistas que siguieron a la proclamación de la independencia el 28 de julio de 1821 pueden ser interpretadas como una de las primeras aplicaciones de esta estrategia de manumisiones en el territorio peruano. La débil cantidad de enrolamientos al momento del desembarque de Pisco y el posterior ataque de las fuerzas realistas sobre Lima decidieron a San Martín a profundizar sus medidas, pese a las protestas de los hacendados propietarios de esclavos, que quedaron muy descontentos ya que, a cambio, no se les ofreció ninguna compensación.

La Declaración de la Libertad de Vientres el 12 de agosto de $1821,{ }^{26}$ con el fin de la trata negrera (24 de noviembre de 1821), estaba compuesto por textos escritos de Bernardo de Monteagudo en la misma línea de los precedentes redactados en Argentina y Chile. Sin embargo, para no alienárselos del todo apenas se alejó la amenaza realista, San Martín sacó otro decreto en el que dejaba sin efecto las antiguas medidas. Paralelamente, para evitar las sublevaciones de descontentos en sus filas, organizó algunos sorteos de libertad. Cuando San Martín se marchaba en 1822, Simón Bolívar recuperó los soldados esclavos incorporándolos a sus tropas, mas no bastó para oponerse al potente contraataque realista que se apoderó de Lima durante un mes (del 13 de junio al 16 de julio de 1823).

1. La llegada de Simón Bolívar confirmó la tendencia antiesclavista de la naciente república. La nueva constitución liberal del 12 de noviembre de 1823 se reclamaba claramente antiesclavista en su artículo 11: "Nadie nace esclavo en el Perú; ni de nuevo puede entrar en él, alguno de esta condición. Queda abolido el comercio de negros"; en su artículo 12: "el peruano que fuere convencido de este tráfico, pierde los derechos de naturaleza"; y en su artículo 13: "El extranjero que se ocupare de él, no puede naturalizarse en el Perú".

2. En previsión de los futuros enfrentamientos de Junín y Ayacucho (1824), se sistematizó las levas de esclavos, y cuando el Libertador se marchó del Perú (en septiembre de 1826) no efectuó ninguna devolución de sus soldados a sus antiguos propietarios. ${ }^{27}$

\footnotetext{
26 Ver en el cuadro III el contenido del Decreto extraído de José A. de la Puente Candamo, ed., Periódicos (Lima: Comisión Nacional del Sesquicentenario de la Independencia del Perù, 1972-1973).

27 Basadre Grohmann, Historia de la República del Perú (Lima: Ed. Universitaria, 1966).
} 
Entre tanto, en 1825, cuando Bolívar estaba todavía en el Alto Perú, los conservadores proesclavistas, como el caudillo Elías, de la Costa norteña, aprovecharon para reanudar el tráfico negrero, el aplazamiento y la anulación de las manumisiones militares, la introducción de una papeleta de tránsito, y encabezar una lucha feroz contra el cimarronaje, hasta dar facilidades fiscales con la reducción del impuesto de alcabalas para los compradores de esclavos. De esta forma, se hicieron fuertes los caudillos del norte, con el objetivo de hacer fracasar el proyecto federalista bolivariano. La ruptura sería totalmente consumida con el desprendimiento de Bolivia ese mismo año. Los caudillos, tanto del norte como del sur, estrecharon lazos para combatir la influencia de la Gran Colombia, que recayó después de las paces con Bolivia y la frustrada guerra de Tarqui, donde el Perú tuvo que renunciar a Guayaquil (1829).

Debilitándose el enemigo que los cohesionaba, la discordia y lucha por el poder comenzó a oponer los caudillos entre ellos. El país se hundió en luchas intestinas en las que el historiador Paul Gootenberg discierne dos principales bloques: el bloque conservador del Norte -que respaldaba los intereses de los hacendados- y el bloque liberal del sur — que se apoyaba sobre el emergente comercio de la lana. En este periodo, que fue de 1825 a 1845, es decir, 20 años, se sucedieron diez "presidentes" alcanzando un clímax de violencia particular durante la construcción y luego el desmantelamiento de la confederación peruano-boliviana (18361839), cuyo golpe mortal vino del ejército restaurador encabezado por los caudillos Gamarra (peruano) y Bulnes (chileno). En este episodio, tampoco R. Castilla perdió la ocasión de distinguirse, pero esta vez alcanzó la consagración de héroe nacional durante la Batalla de Yungay. ${ }^{28}$

Entre 1842 y 1844, el Perú se libró de una cruda guerra de caudillos llegando a tener cinco presidentes en dos años. Castilla tomó parte de estas luchas pretextando defender la constitución conservadora de 1839 contra las fuerzas "dictatoriales" de Vivanco. Ahora bien, recordemos con precisión que Vivanco estaba en excelentes términos con el cónsul inglés Pitt Adams y que el 12 de agosto de 1843 había emitido un decreto contra la importación de esclavos de países vecinos. ${ }^{29}$ Sin embargo, esta alianza no bastó para que Vivanco se mantuviera en el poder y pronto quedó aislado en su ciudad natal de Arequipa donde guerreaba con Castilla. Por consiguiente, asistimos este año de 1844 a un replanteamiento de las fuerzas caudillistas en el que fueron partícipes las potencias extranjeras. ${ }^{30}$ Castilla fue el caudillo que supo mejor negociar, ya fuera con sus contrincantes, ya fuera con los franceses, que estaban tan interesados como los británicos en el salitre/huano de Tarapacá y las ventajas económicas y financieras. La victoria sobre Vivanco en Carmen Alto el 22 de julio de 1844 y la remisión de Lima pacíficamente por los caudillos Elías y Echenique ${ }^{31}$ marcaron la culminación de su tortuoso ascenso hacia el poder. Solamente en un segundo momento, se procedió a la

28 Scarlet O’ Phelan Godoy, “Santa-Cruz y Gamarra: el proyecto de la confederación y el control político del sur Andino”, en Guerra, región y nación: La confederación Perú-Boliviana (1836-1839), eds. Carlos Rojas Donoso y Jaime Rosenblitt (Santiago: Dirección de Bibliotecas, Archivos y Museos, 2009).

29 Vivanco prohibió el trafico intercontinental, declarando libres a penas tocaran el suelo peruano los esclavos importados de los países vecinos como Colombia, Ecuador, etc. Léase Manuel Saponara, Inglaterra y la abolición de la esclavitud en el Perú: Aspectos de la política pública (1820-1854) (Lima: Fondo editorial del Congreso del Perú, 2008), 132-133.

30 Referirse a Celia Wu Branding, Generales y diplomáticos: Gran Bretaña y el Perú (1820-1840) (Lima: PUPC, 1993). Igualmente a Fabián Novak Talavera, Las relaciones entre el Perú y Francia (1827-2004): Política Exterior Peruana (Lima: PUCP, 2005). Asimismo, para los más interesados, la correspondencia diplomática de los cónsules franceses en Lima, presente en el Centro de Archivos Diplomáticos de los Asuntos Exteriores, Nantes, Lima, Consulado, 2MI 1775 hasta 2MI 1783.

31 El 17 de junio de 1844, Domingo Elías se autoproclamó Jefe de Estado aprovechándose de la ausencia de Vivanco en la capital y mandó reanudar con el tráfico interamericano que nunca había parado, pero que se había debilitado con las proclamaciones de los Independentistas. El historiador Jacobsen estima que fueron 500 los esclavos introducidos legalmente en aquella época. Cf. Jacobsen, Op. Cit. 
legitimización política de las acciones militares vía un procedimiento bastante artificial en el Congreso, donde se nombró a Ramón Castilla Presidente de la República del Perú.

\section{La sintomática ausencia abolicionista y el sorpresivo decreto de Huancayo el 3 de diciembre de 1854}

Vale la pena señalar que, al marcharse Simón Bolívar del territorio peruano, se relegó la problemática de la esclavitud a un segundo plano, cajilla de la que sería muy difícil salir después. Las luchas intestinas entre caudillos tuvieron como consecuencia una esclerosis en la sociedad peruana que se refleja tanto en los periódicos, como en el debate jurídico y leyes contra corriente. No existió en el Perú muchas asociaciones progresistas, menos aun una abolicionista. Incluso, el periódico más fuertemente marcado por la corriente liberal como El Comercio no orientó claramente el debate hasta el año 1954; es decir, que tomó posición tarde.

Cuando el chileno Manuel Amunátegui y el argentino Alejandro Villota fundaron un diario en 1839,32 el objeto primero era la divulgación de la información fuera cual fuera. Por ello, se pueden encontrar extractos completos de un debate sobre la legalización de la internación de esclavos en el Perú en 1845. En efecto, desde la proclamación de San Martín hasta finales del siglo, los esclavistas hicieron múltiples y poderosos intentos contra corriente. Incluso, en algunas ocasiones, se salieron con la suya como veremos a continuación.

En 1841, los hacendados esclavistas lanzaron una nueva ofensiva para importar esclavos de Colombia, dirigida al Consejo de Estado, bajo el portavoz del hacendado costeño Francisco Calvo. Con la remodelación política en 1845, el Consejo de Estado "Castillano" quería marcar su distanciamiento con los postulados esclavistas. De allí, la voluntad de dar a conocer al público el debate y el negativo resultado de este intento esclavista. El periodista de El Comercio P. J. Flores se encargó de informar sobre los principales puntos de este asunto de manera crítica. Su argumentación denunciaba el paternalismo, la hipocresía y los chatos argumentos economicistas. Decía así: "Esta pretensión tan contraria a las luces del siglo encontró una justa y unánime oposición en todas las personas y clases notables de la República, por cuyo motivo se vio precisado su autor a abandonarla". ${ }^{33}$

El periódico concurrente El Peruano aprovechó la polémica y el interés del público, traduciéndose en términos de ventas, para responder a P. J Flores manteniendo el suspense durante todo un mes. Asimismo, en esta presentación rápida de los periódicos, se tiene que mencionar al diario, mucho más conservador, El Nacional.

De modo sintético, lo que estaba en juego era la supervivencia de un antiguo tráfico negrero interamericano que, desde la época colonial, unían Cartagena y Lima. Entre 1841 y 1847, se calcula en varios cientos los esclavos y libertos del Chocó que fueron internados en el Perú. Esta cruel realidad era sabida por los contemporáneos que, ya la combatían, o ya, por lo contrario, intentaban legitimarla o hipócritamente ignorarla.

La polémica alcanzó un nivel antes nunca conocido en el año de 1845: el Consejo de Estado liberal y el Senado conservador se disputaban el poder. De modo que, cuando el Consejo votó a favor de la supresión, unos meses después, el Senado legitimaba la trata. Los periódicos

32 "Historia del grupo comercio", El Comercio (Lima: grupo El Comercio, 2012). Disponible en http://grupoelcomercio.com.pe/info (consultado el 27 de octubre de 2012).

33 J. P. Flores, El comercio, 26 de junio, 1845, disponible en Biblioteca Central, Fondos Reservados de la Universidad Nacional Mayor de San Marcos: UNMSM, Lima. 
nos sumergen en la cotidianidad del debate y en la cosmovisión de aquella época. Lamentablemente, ninguno de ellos aborreció claramente los colores del abolicionismo como explica el antropólogo H. R. Pastor. En el corazón del problema, encontramos la falta de voluntad política por parte de la mayoría de liberales peruanos que no sólo se nutría de una de las tradiciones más conservadoras entre los partidos liberales de Europa así como la de España, sino que para remate, sus miembros más eminentes como Elías o Mateo Paz Soldán eran esclavistas. No es de extrañar que, al mismo tiempo que Flores aleccionaba a Francisco Calvo en El Comercio, el esclavista podía enterarse de lo último de las ventas de la esclavatura leyendo la sección "Comunicados".

Quizás, muy progresivamente, conforme los postulados abolicionistas iban ganando terreno, El Comercio iba estrechando más y más lazos con los abolicionistas. Durante el episodio revolucionario de la esclavatura en Trujillo en 1851, guardó todas sus precauciones, que tan sólo abandonaría en el momento de la gran manumisión por parte de Alfonso Gonzales Pinillos, que perdonó y liberó sus 130 esclavos. ${ }^{34}$

El diario no perdió la oportunidad de evocar esta tan generosa y simbólica "libertad gracia", relanzando el debate, que era lo que apuntalaba el abolicionista criollo Pinillos. Así pues, transcurrió el primer mandato de Castilla con una suerte de hibridación extraña en lo político de la escuela conservadora herrerista y de elementos del liberalismo económico. Su sucesor Echenique, menos dotado que su predecesor para ensamblar y neutralizar la competencia política, se fue gastando en guerras con los demás caudillos: San Román, Vivanco, Manuel Tarfur, Elías y Castilla.

Paralelamente, en sus relaciones con las potencias extranjeras, la balanza se inclinó definitivamente a favor de Inglaterra, en detrimento de Francia y otras potencias. En el corazón de este replanteamiento, radicaba el huano que había posibilitado tanto la consolidación de la deuda externa peruana y la corrupción, como el financiamiento de los caudillos, empezando por Castilla. Por lo tanto, el problema de los fondos para la guerra dejó de ocupar el primer lugar, desplazado por el del contingente. Mostrando el ejemplo, el caudillo Manuel Tarfur decretó la abolición de la esclavitud y del tributo indígena (1853) esperanzado por un alistamiento masivo para fortalecer su intentona en la frontera con Ecuador. Recordemos que este pequeño país fronterizo había proclamado medidas similares un año atrás mediante la actuación del general José María Urbina (1852), que se benefició mucho de dichas medidas populistas. Un año después, el fallido intento de Tarfur rebrotó la temática abolicionista en una suerte de subasta entre Castilla y Echenique.

En una postura más frágil que la del presidente Echenique, que gozaba de la armada regular, Castilla tuvo que ingeniárselas para reclutar masivamente y compensar así la falta de armamento por el número de soldados. Indisociablemente, la abolición de las castas y del tributo indígena el 2 de agosto de 1854 fue de par con la estrategia militar castillista. Al ver la eficacia de esta proclamación, su contrincante decidió apoyarse sobre la manumisión militar inmediata, viejo truco de los tiempos independentistas que había funcionado de maravilla. De todos modos, le resultaba difícil ofrecer más, ya que si no, hubiera perdido el apoyo de los hacendados esclavistas del norte. En una nueva puja y en previsión de una pronta confrontación con Echenique, Castilla decretó la abolición total de la esclavitud el 3 de diciembre de 1854 en Huancayo, asegurándose definitivamente no sólo los reclutas, sino el apoyo popular que hizo tanta falta a Echenique. El primer grupo fue diezmado y luego los refuerzos se retrasaron, lo

34 Jorge Basadre Grohmann, Historia de la República del Perú, vol. 4 (Lima: Ed. Universitaria, 1966), 37-39. 
cual acarreó una verdadera estampida para el ejército regular; incluso algunos soldados en la desesperación cambiaron de bando. Ahora bien, si ponemos entre comillas toda la mitología militar que rodea la victoria de La Palma, nos damos cuenta de que el número de contingente y pérdidas no han sido más hondamente verificadas.

\section{CONCLUSIÓN}

Si nos circunscribimos al periodo de las tempranas Repúblicas después de los vaivenes de las levas para la Independencia, cabe constatar que el tema de la esclavitud y la supervivencia de la trata pasaron a ocupar un segundo plano en el debate público en todo el continente americano. Quizás Chile, México y la Confederación Centroamericana destacaron como distinguidas excepciones de un sintomático desinterés continental. Y no por falta de rebeldía y combatividad de los esclavos, sino por el silenciamiento de los gobiernos de caudillos, unos menos conservadores que otros, pero ninguno realmente abolicionista. Es más, una gran mayoría de caudillos asumió posiciones francamente contra corriente de la modernización mental mundial encabezada por Haití. Por ello, no es extraño la sí escasa producción escrita que evidencia la censura que funcionaba a pleno régimen en el sistema autoritario peruano, así como en los demás países. La relevante ausencia de voces esclavas pone en evidencia la coercitiva relación de fuerzas en las sociedades hispanoamericanas.

Por otra parte, existió una suerte de indiferencia frente al sufrimiento esclavo heredado de los tiempos coloniales y que se seguía nutriendo con arraigados complejos culturales y raciales. El antropólogo H. Rodríguez Pastor denuncia una política global de enajenación de la problemática afroibérica y nos hace recordar que: "No existió en el Perú ni un verdadero movimiento abolicionista ni una estrategia bien definida, pero voces dispersas por aquí por allá", lo cual no favoreció la eficacia ni la visibilidad de los argumentos abolicionistas. Sintomática fue la ausencia de sociedades abolicionistas en el continente, constituyéndose las primeras por las mismas fechas que La Sociedad Abolicionista Española, es decir, ya a finales del siglo XIX.

\section{REFERENCIAS}

Ali, Omar H. Abolicionismo en Americas: hacia un estudio comparativo de Historia Mundial. Bogotá: Pontifica Universidad Javeriana, CASO, Tawson University, 2005.

Anderson, Benedict. Imagined Communities: reflections on the origin and spread of nationalism. London: Verso, 1991.

Barros Arana, Diego. Historia Jeneral de Chile, vol.10. Santiago de Chile: R. Jover, 1886.

Basadre Grohmann, Jorge. Historia de la Republica del Perù. Lima: Ed. Universitaria, 1966.

Bataillon, Gilles. Genesis de las guerras intestinas en America central: 1960-1983. 1a ed. Buenos Aires: Fondo de Cultura Económica, 2008.

Berruezo, María Teresa. La participación americana en las Cortes de Cadiz (1810-1814). 1a ed. Madrid: Centro de Estudios Constitucionales, 1986.

Blancpain, François. La colonie française de Saint-Domingue. Paris: Karthala, 2004.

Blancpain, François Haiti et la République dominicaine: une question de frontières. Guyane: Ibis Rouge, 2008. 
Cayo Cordova, Percy. Ramon Castilla. Lima: Brasa, 1994.

Centro de Desarrollo Étnico, ed. Mira como me ves: racismo y esteriotipos etnicos en medios de comunicacion. Lima: CEDET, 2010.

Coleccion Documental de la Independencia del Perù, tomo XIII, vol. 2, Obra de Gobierno y Epistolario de San Martín, ed. José A. de la Puente Candamo. Lima: Comision Nacional del Sesquicentenario de la Independencia del Perú, 1975.

Colectivo, Volumen. Documentos historicos del Perù. Lima: Cia. de Impresiones y Publicidad, 1946.

Consejo Superior de Investigaciones Científicas y Centro de Estudios Históricos. Coloquio Internacional sobre la Abolicion de la Esclavitud (Madrid 1986): Esclavitud y Derechos Humanos. Madrid: Consejo superior de Investigaciones Científicas y Centro de Estudios Históricos, 1990.

Contreras, Carlos y Marcos Cueto. Historia del Perú contemporánea. 4a ed. Lima: IEP, 2010.

El Comercio. «Historia del grupo comercio», 2012. Disponible en http:/ / grupoelcomercio. com.pe/info.

Flores, J. P. El comercio, 26 de junio, 1845.

Ghorbal, Karim. Reformisme et esclavage à Cuba (1835-1845). Paris : Publibook, 2009.

Guerrero Cano, María Magdalena. Santo Domingo (1795-1865). Cadiz: Servicio de publicaciones Universidad de Cádiz, 1986.

Guerrero Domínguez, Ángel Luis. «Lex et Bellum: Fuero militar y milicias en el norte del virreinato de Perù a finales del siglo XVIII». En Las armas de la nacion: Independencia y Ciudadania en Hispanoamerica (1750-1850). Madrid: Iberoamericana, 2007.

Instituto Libertador Ramon Castilla. Memoria del bicentenario del nacimiento del Gran Mariscal Don Ramon Castilla (1797-1997). Lima: Instituto Libertador Ramon Castilla, 2001.

Jacobsen, Nils. The Development of Peru's Slave Population and its Significance for Coastal Agriculture (1792-1854). Los Angeles: UCLA, 1974.

Kuerthe, Allan J. y Juan Marchena. Soldados del Rey: el Ejército Borbónico en América colonial en vísperas de la Independencia. Castelllo de la Plana: Universitat Jaume I, 2005.

Marchena, Juan y Manuel Chust. Armas de la nación: independencia y ciudadania en Hispanoamerica. Madrid : Iberoamericana, 2007.

Novak Talavera, Fabián. Las relaciones entre el Perú y Francia (1827-2004): Política Exterior Peruana. Lima: PUCP, 2005.

O' Phelan Godoy, Scarlet. "Santa-Cruz y Gamarra: el proyecto de la confederación y el control político del sur Andino". En Guerra, región y nación: La confederación Perú-Boliviana (1836-1839), eds. Carlos Rojas Donoso y Jaime Rosenblitt. Santiago: la Direccion de las bibliotecas, archivos y museos, 2009.

Riviale, Pascal. Una historia de la presencia francesa en el Perú, del siglo de las luces a los años locos. Lima: IEP, 2008.

Rodríguez Asti, John. El discurso abolicionista en la prensa peruana (1800-1850): una aproximación al tema, vol. 2. Lima: PUCP, Instituto Riva-Agüero, 1998.

Rouquié, Alain. L'Etat militaire en Amerique Latine. Paris: Editions du Seuil, 1982.

Sagàs, Ernesto. Race and Politics in the Dominican Republic. Gainesville : University Press of 
Florida, 2000.

Saint-Juste, Laurore. "La création de l'emblème de la révolution de l'Amérique espagnole". Revue de la société haitienne d'histoire et géographie, no.4 (mars, 1983): 28-38.

Sales de Bohigas, Nuria. Esclavos, reclutas y mercaderes de quintos. Barcelona: Ariel, 1974.

Saponara, Manuel. Inglaterra y la abolicion de la esclavitud en el Perú: aspectos de la política pública (1820-1854). Lima: Fondo Editorial del Congreso del Perú, 2008..

Schmidt, Nelly. L'engrenage de la liberté: Caraibes XIXème siècle. Aix-en-Provence: Imprimerie d'Aix-en-Provence, 1995.

Timothy E, Anna. «The Peruvian Declaration of Independence: Freedom by coercion». Journal of Latin American Studies 7 (May, 1975), part II.

Vila Vilar, Enriqueta y Luisa Vila Vilar. Los Abolicionistas Españoles. Siglo XIX. Madrid: Cultura Hispánica Instituto de Cooperación Iberoamericana, 1996.

Wu Branding, Celia. Generales y diplomáticos: Gran Bretaña y el Perú (1820-1840). Lima: PUPC, 1993.

Yacou, Alain. De l'île espagnole à la République Dominicaine d'aujourd'hui. Pointe-à-Pitre : Karthala, 2010.

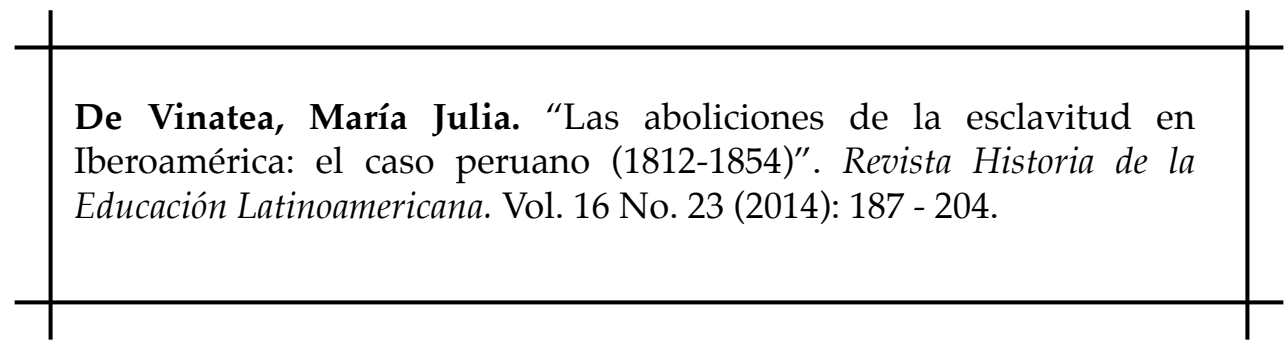

